\title{
Analysis on the Tensile Strength of Post-Installed Large-Diameter Anchors in Concrete
}

\author{
Zhao Ningyu ${ }^{1,2^{*}}$, Zhang Junbo ${ }^{1,3}$ and Jiang Haifei ${ }^{1}$ \\ ${ }^{1}$ School of Civil Engineering, Chongqing Jiaotong University, Chongqing 400074, China \\ ${ }^{2}$ State Key Laboratory of Mountain Bridge and Tunnel Engineering, Chongqing 400074, China \\ ${ }^{3}$ Department of Civil Engineering, University of Liverpool, Liverpool, L693BX, UK
}

Received 4 May 2019; Accepted 15 September 2019

\begin{abstract}
Post-installed large-diameter anchors (PLAs, diameter range: $40 \mathrm{~mm}-150 \mathrm{~mm}$ ) have been widely used in the anchoring of equipment due to their flexible layout. Previous studies on the tensile capacity of PSAs have mainly focused on PLAs with a diameter ranging from $6 \mathrm{~mm}$ to $36 \mathrm{~mm}$, while their formulas for calculating tensile strength have produced great errors as can be seen in their experimental results for large-diameter anchors. To investigate the tensile strength of PLAs, the failure characteristics, ultimate failure loads, loading displacement, and bond stress distribution of PLAs were measured in this study by using 32 full-scale specimens in 8 groups with different anchoring depths and anchor diameters. The full-scale model was applied in an ABAQUS numerical analysis, and the results were compared with the test results. A novel method for calculating the tensile capacity of PLAs was then built while considering both corrected mean bond shearing stress and concrete capacity design (CCD). The results demonstrate that compound bonding failure is the major failure mode of a large-diameter anchor system. Meanwhile, the axial stress of the anchor bolt shows a concave distribution pattern along the anchoring depth. The bond stress of the glue layer conforms to the hyperbolic functional distribution under small loads according to elastic theory but shows an approximately uniform distribution while approaching the ultimate load. Moreover, the bond stress of the glue layer decreases along with an increasing anchor diameter. The results of the finite element simulation conform well to the test results, thereby highlighting the reliability of the proposed calculation method. The conclusions also provide theoretical references for calculating the tensile strength of PLAs.
\end{abstract}

Keywords: Post-installed large-diameter anchor; Failure mode; Bond stress; Tensile strength

\section{Introduction}

Some large mechanical equipment and devices have high installation accuracy requirements (e.g., the deviation of central axis must be smaller than $1 \mathrm{~mm}$ ) during construction or reconstruction in industrial fields, such as metallurgy, chemical engineering, electricity, shipping, and nuclear power. Moreover, pre-buried anchors cannot be located accurately, and the engineering environment may impose some geological limitations. As a result, post-installed chemical anchors with flexible designs and layouts have been widely used as anchoring foundations in these fields. The diameter $(d)$ of post-installed chemical anchors typically ranges from $40 \mathrm{~mm}$ to $150 \mathrm{~mm}$. Tensile strength is the principal mode of a post-installed anchor system. According to the tensile test results of small-diameter anchors $(6 \mathrm{~mm}<$ $d<36 \mathrm{~mm}$ ), post-installed anchors have three tensile failure modes, namely, concrete cone failure, compound failure (cone + bonding section), and bolt steel failure. Compound failure generally occurs at an anchoring depth of $6 d$ to- $20 d$ and can be further divided into cone + bolt-glue-concrete interface failure, cone + glue-concrete interface failure, and cone + glue-bolt interface failure (Fig.1).

Given the weight and dynamic loads of heavy equipment, the steel failure mode of anchor bolts must be

*E-mail address: zny2008@163.com

ISSN: 1791-2377 C 2019 School of Science, IHU. All rights reserved.

doi:10.25103/jestr.125.13 determined during their design. Therefore, the anchoring depth must be increased and the concrete basis must be expanded, but doing so may lead to poor drilling perpendicularity, glue injection, solidification, and maintenance, thereby making these solutions practically infeasible. For the compound failure of anchors at a $6 d$ to$20 d$ depth, the tensile capacity can be measured by conducting a few field tests, but the results of these tests are often unreliable. Given the limited theoretical understanding of the compound failure mode, anchoring system failure incidents caused by non-scientific design and construction have occurred frequently and lead to other engineeringrelated accidents.

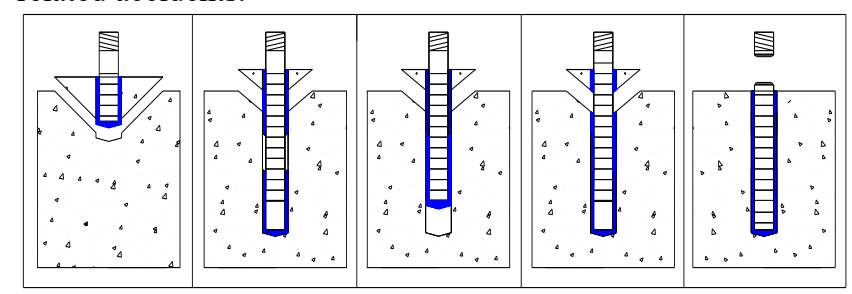

Fig. 1. Tensile failure modes of post-installed anchors

Previous studies on post-installed anchors have mainly focused on anchors with diameters ranging from $6 \mathrm{~mm}$ to $36 \mathrm{~mm}$. However, an experimental study reveals that postinstalled large-diameter anchors(PLAs) have unique failure modes that differ from those of small-diameter anchors[1-2]. 
As the diameter of anchor bolts increases, their failure modes are changed, which subsequently lead to changes in both bond strength and distribution. However, theoretical studies on such changes have been few.

To address this research gap, a method for calculating the tensile capacity of PLAs based on corrected mean bond stress and concrete capacity design (CCD) is proposed in this study by analyzing abundant amounts of test data to provide some theoretical references for calculating the tensile strength of PLAs.

\section{State of the Art}

A network is normally represented by a graph that is composed of a set of nodes and edges. The task of network clustering is to divide a network into different clusters based on certain principles. Each cluster is called a community.

Many studies on post-installed anchors have been conducted from the perspectives of failure mode, load-transferring mechanism, mechanical model, and design method in order to develop a systematic design method. The failure of the anchoring system under different mechanical states can be divided into failure under axial loads, shearing state failure, and edge failure. In their experimental studies conducted with different anchoring parameters, Cook et al. [3-5] categorized the failure modes under tensile loads into four types: concrete cone failure: the anchoring depth $\left(h_{e f}\right)$ ranges between $3 d$ and $5 d$, and the failure strength is dominated by the tensile performance of concrete; bond failure: the inadequate bonding strength is caused by the poor adhesive or unreasonable anchoring; steel failure: the anchoring depth exceeds the tensile strength of the steel materials of the anchor bolt; and compound failure: the compound failure mode of shallow concrete cone and bonding failure under an anchoring depth of $6 d$ to20d. Among these failure modes, compound failure can be further subdivided into glue-concrete interface failure, glue-bolt interface failure, and glue-concrete-bolt interface failure (Fig.1), concrete cone failure and bond failure should be avoided in engineering projects, and steel failure is often restricted by the size of the anchoring base. To address the problems related to the occurrence time of cone and beneath bonding failure, Michael et al. [6-7] carried out a displacement test based on the concrete cone surface and gradation loading of anchor bolts and hypothesized that the cone and bond would fail simultaneously. This hypothesis was supported by the experimental results of Cook et al.[8] In addition, increasing the diameter of anchor bolts (or drilling holes) can change the failure modes. For instance, Zhao et al. [2] observed a double shallow concrete cone failure in M36, M48, and M72 anchors with a drilling hole diameter of $1.1 d$, whereas. J.Appl et al. [7] observed this failure mode in an M24 anchor with a drilling hole diameter of $50 \mathrm{~mm}$.

Previous studies on the load-transferring mechanism under tensile loads reveal that the anchoring system transfers axial tensile force on the anchor bolt onto the anchoring base through chemical bonding, mechanical occlusion, and friction among the anchor bolt, glue layer, and concrete. Based on the load-displacement curves of the anchor bolt and cone, Fuchs et al. [9] identified the two-stage brittle characteristics of the anchoring system from elastic failure to plastic failure. Zhou et al. [10] deduced the distribution curve of bond stress in the elastic stage. Eligehausen et al.
[11] obtained the distribution curve of bond stress along anchoring depth through a numerical simulation. KeunHyeok et al. [12] revealed the distribution of bond stress by measuring the axial strain of the anchor bolt, and then analyzed the reasonability of the distribution proposed by Eligehausen. They found that unlike the steel bar-concrete bonding, the interface bonding strength on a concrete-free surface is not equal to 0 , and that the distribution curves show different shapes as they approach the failure loads. Mahrenholtz et al. [13] observed a faint attenuation in bond stress in their test of M12, M16, and M24 anchor bolts. However, their findings were rejected by Akanshu et al. [14] and were generally ignored by other researchers. In their experiments with M36, M48, and M72 anchor bolts, Zhao et al. [2] found that bonding strength significantly decreases along with an increasing anchor bolt diameter.

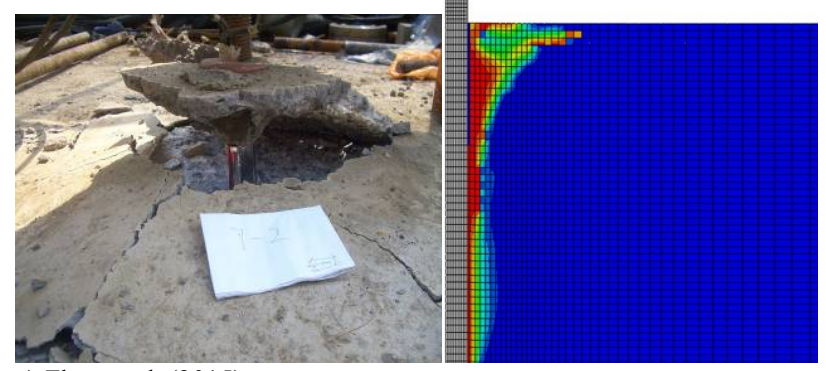

a) Zhao et al. (2015)

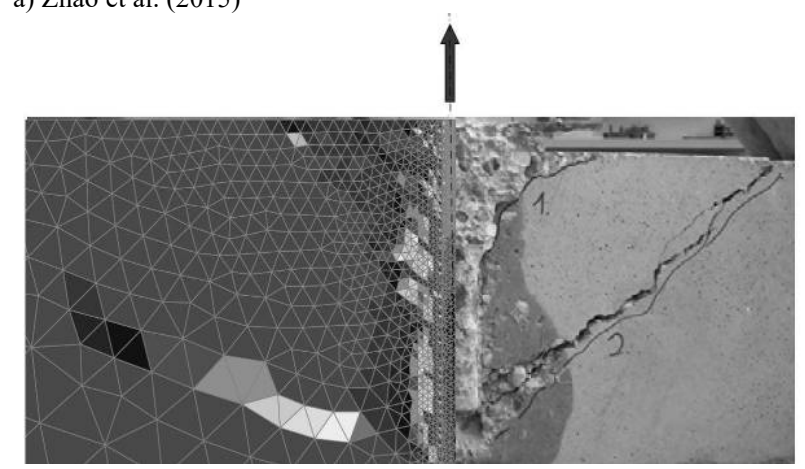

b) J.Appl (2003)

Fig. 2. Double-cone failure mode

Three methods for calculating the mechanical model and tensile capacity have been reported in the literature. The first is Elasticity model: on the basis of elastic theory and by ignoring the glue layer and failure modes, Muratli et al. [15] proposed a formula that calculates the elastic tensile capacity of a post-installed anchoring system following the minimum potential energy principle. Given that this formula only considers the elastic tensile capacity of the anchoring system, its resultsare far lower than the ultimate tensile capacity measured in the test. Moreover, some parameters need to be acquired from the standard test, thereby limiting the flexible application of this formula. Delhomme et al. [16] described the mechanical properties of concrete in the concrete cone + glue--concrete interface compound failure by using the Mohr-Coulomb criteria, and then proposed some formulas for calculating cone height and fracture slope. On the basis of these formulas, they devised a method for calculating the ultimate tensile capacity of cone + bonding failure. However, this method has poor reliability as can be seen in the huge discrepancies between the calculation and test results. Shutong Yang et al. [17] ignored the existence of a shallow cone and regarded the bonding layer as a shear lag model. They devised a method for calculating the of tensile capacity of the bolt-glue interface failure mode and hypothesized that 
the failure interface differs from the concrete-glue interface failure studied by Mahrenholtz et al. (2013) and Zhao et al. (2015). In addition, the calculated bond stress distribution in their numerical simulation significantly differed from that in their test. The second is Model and method based on CCD: Fuchs et al.[9] proposed a CCD method to cope with the cone failure of pre-buried and mechanical post-installed anchors (applied by ACI318 and ETAG001 codes). Thus far, this method has been widely recognized as the most mature technique for measuring tensile capacity. Ožbolt et al. [18] corrected the parameters of the CCD model by using an experimental statistical method and then proposed a formula for calculating the tensile capacity of a post-installed single anchor. Mallee et al.[19] calculated cone height by using the CCD formula and then proposed a method for computing compound failure mode by combining this mode with the tensile capacity of bond failure below the cone. Generally, these methods avoid the compound failure mode of chemical post-installed anchors and fail to explain the sources of tensile capacity from the mechanical mechanism. The third is Uniform bond stress (UBS) model: The UBS model was originally a mechanical model that calculates the bonding area based on anchor bolt diameter. This formula was proposed by Cook[20], who hypothesizedthat the tensile capacity of the shallow cone only accounts for a small proportion of the total tensile capacity, that bond stress shows a uniform distribution along the anchoring section, and that the glue-concrete interface failure is indistinguishable (or difficult to distinguish) from the gluebolt interface failure of the thin glue layer. In the UBS model, tensile capacity is computed as $N_{u}=\pi \tau d h_{e f}$. Bride et al.[21] and Eligehausen et al.[22] later found in their numerical simulations that although the distribution of bond stress along the length of a cone becomes relatively complex while approaching the ultimate loads, a uniform distribution can be observed in most regions below the cone. Sadie[23] performed a statistical analysis of anchor bolts with diameters below the range of $6 \mathrm{~mm}$ to $-24 \mathrm{~mm}$ and found that bond stress $\tau$ is stable for a fixed glue variety. At present, this model has been widely accepted by researchers.

Previous studies on post-installed anchors have mainly focused on anchors with diameters ranging from $6 \mathrm{~mm}$ to$36 \mathrm{~mm}$. To propose a method for calculating the ultimate bearing capacity of PLA, the failure mode of PLA, and the evolution law of tensile capacity, this study quantified the influence of bond strength attenuation by conducting a fullscale failure test and numerical simulation. A calculation model of tensile strength that adapts to the size effect of large-diameter anchors was also built. The conclusions of this work provide a theoretical basis for calculating the tensile strength of PLAs.

The rest of this study is organized as follows. Section 3 introduces the experiment design and defines the finite element modeling parameters. Section 4 analyzes the test and numerical simulation results and presents a method for calculating the ultimate bearing capacity of PLAs based on corrected mean bond stress and CCD. Section 5 concludes the study.

\section{Methodology}

\subsection{Experiment}

\subsubsection{Design and manufacturing of specimens}

A total of 32 tests were carried out. Four diameters $(36,48$, 90 , and $150 \mathrm{~mm}$ ) were set, and the anchoring depths of each diameter were set as $8 d$ and $12 d$. The design strength grade of the concrete base in the tests was C30. Given that the ultimate tensile strength of a large-diameter anchor is significantly higher than that of a small-diameter anchor, all tested anchors were placed on a whole piece $(12 \mathrm{~m} \times 6 \mathrm{~m} \times 3 \mathrm{~m})$ of pouring concrete base. No steel bar was embedded into the concrete base to avoid influencing the test results. A rodlike anchor bolt with several ring grooves in the anchoring section made of Q345 steel was used. The space of the test anchor bolts was set to $3 h_{e f}$ to prevent the mutual influences of adjacent anchor bolts. Hilti HIT-RE500 glue was used. The parameters of materials are shown in Table 1.

Table 1. Parameters of materials

\begin{tabular}{|c|c|c|c|c|}
\hline \multicolumn{2}{|c|}{ Materials } & $\begin{array}{c}\text { Tensile } \\
\text { stress }\end{array}$ & $\begin{array}{c}\text { Yield } \\
\text { stress }\end{array}$ & $\begin{array}{c}\text { Tensile } \\
\text { strength }\end{array}$ \\
\hline $\begin{array}{c}\text { Concrete } \\
\text { base }\end{array}$ & $\mathrm{C} 30$ & 32.9 & - & - \\
\hline $\begin{array}{l}\text { Anchor } \\
\text { bolt }\end{array}$ & Q345 & - & 468 & 584 \\
\hline $\begin{array}{l}\text { Bonding } \\
\text { glue }\end{array}$ & $\begin{array}{c}\text { HIT- } \\
\text { RE500 }\end{array}$ & 120 & - & 51.5 \\
\hline
\end{tabular}

To guarantee the accuracy of drilling perpendicularity and concentricity under a large drilling depth, a JX-1 geological drilling rig with a special custom-made 2-m-long thin-walled diamond drill was used. The pore diameter was computed as $d+10 \mathrm{~mm}$, and the drilling depth was taken as the effective anchoring depth $h_{e f}+20 \mathrm{~mm}$. Afterward, the hole wall was carefully cleaned by an iron brush. The holes were then cleaned and dried by high-pressure compressed air.

In anchoring construction, glue was initially injected before inserting the anchor bolt. The glue HIT-RE500 was prepared with a proportion of 1:3 and was injected by using a special mixed tube extender. The entire injection was finished before the initial set of glue to prevent the acceleration of the excessive heat by solidification of the glue. This process was controlled within 10min. Anchor bolts were inserted spirally and slowly to prevent the glue from filling the spaces entirely. The specimens were cultured for $24 \mathrm{~h}$ under a standard environment.

\subsubsection{Loading and measurement in tests}

To measure the stress distribution in the anchor bolt, grooves were inserted along the buried depth of the anchor bolt, and a strain gauge was posted every $50 \mathrm{~mm}$ to $100 \mathrm{~mm}$ (determined according to anchoring depth). The scale length of the strain gauge was $3 \mathrm{~mm}$. Displacement detectors were installed on the concrete surface and bolt to measure the displacement of the anchor bolt and concrete base surface. In the tests, loads were applied by 4 electric oil pumps to $320 \mathrm{t}$ hydraulic jacks. Around $10 \%$ of the pre-estimated loads were applied in each stage, and a total 10 stages were set. Each loading stage was stabilized within $2 \mathrm{~min}$, and the rod displacement, surface displacement, and numerical value of each strain gauge were read after each loading stage. These data were read again after the pressure stabilization. This process continued until the preset load or anchoring failure was reached. The experimental apparatus and distribution of strain measuring points on the anchor bolt are shown in Figs. 3 and 4. 


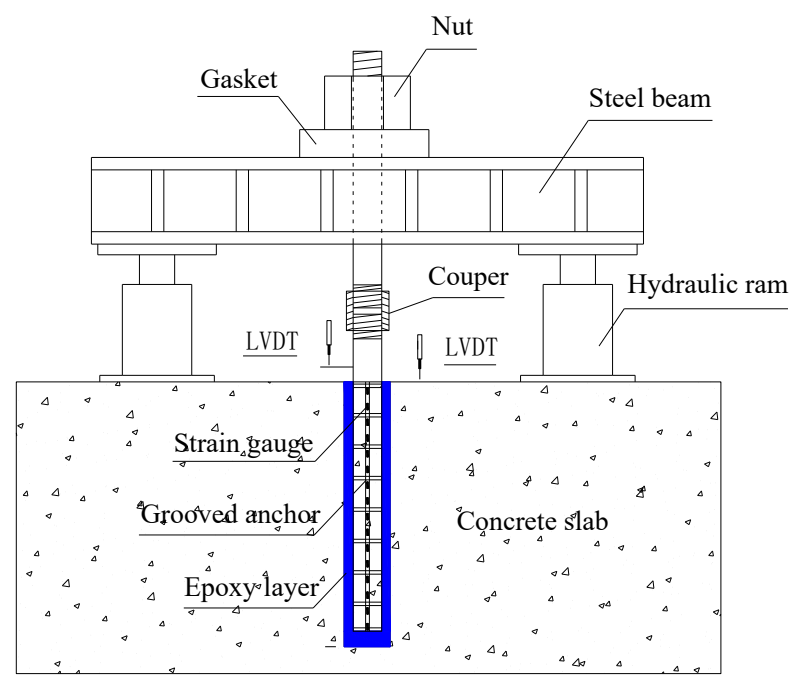

Fig. 3. Experimental apparatus

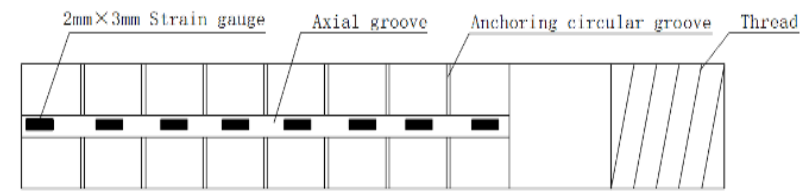

Fig. 4. Anchor bolt structure and strain gauges

\subsection{Finite element modeling}

Concrete materials were prepared by using the plasticdamage model for concrete (CDP) in ABAQUS and based on the damage plastic constitutive model proposed by Lubliner[24]. The stress-strain relation of the CDP model applied the constitutive relation given in the Specification for the Design of Concrete Structures (GB5001-2010). The linear elastic model was applied in the elastic stage, and the stress-strain relation in GB5001-2010 was applied in the non-elastic stage. The concept of damage factor was introduced in the base material to describe the stiffness degradation of materials. The numerical values of the damage factor were then calculated according to the following nonlinear stress-strain relation of concrete:

$$
d_{k}=\frac{(1-b) \varepsilon^{i n} E}{a_{k}+(1-b) \varepsilon^{i n} E},(k=T, C)
$$

Where $T$ and $C$ represent tensile and compression, $b$ is the proportional coefficient of plastic and elastic strains, and $\varepsilon^{i n}$ is the non-elastic strain at the concrete tensile state. The bonding between the concrete and anchor bolt applied the cohesive element model of the damage evolution law based on displacement. The glue-concrete and glue-bolt interfaces adopted the binding constraint. To prevent the steel material failure of the anchor bolt, the ideal elastic-plastic model of skew lines + horizontal lines was applied .Both the concrete and anchor bolt were simulated by using hexahedral quadratic reduction integral elements with eight nodes (C3D8R). Numerical calculation conditions included 14 diameters ranging from $30 \mathrm{~mm}$ to $150 \mathrm{~mm}$ and 3 buried depths $(8,10$, and $12 d)$ of each diameter. The finite element model is shown in Fig.5.

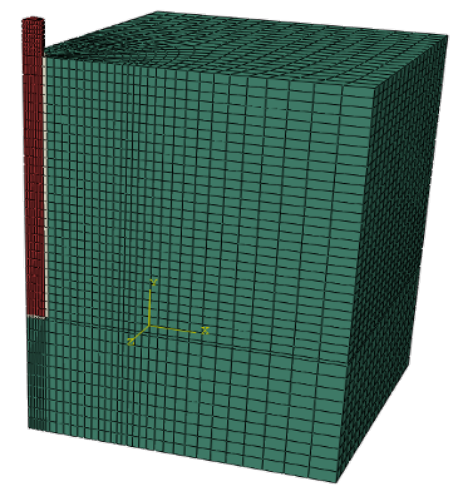

Fig. 5. Numerical model

\section{Results analysis and discussion}

\subsection{Failure modes}

The failure modes of all specimens are consistent at buried depths of $8 d$ and $12 d$. These failure modes mainly include concrete cone + glue-concrete bonding failure or glue-bolt bonding failure. The typical failure modes shown in Figs. 6 and 7 are consistent with the compound failure mode of a small-diameter anchor bolt [3-5].

The height of the failed cone increases along with anchor bolt diameter. The ratio between cone height and anchoring depth $h_{\text {cone }} / h_{\text {ef }}$ ranges from 0.18 to 0.42 , whereas the angle of the failed cone ranges from $30^{\circ}$ to $60^{\circ}$. The radius of the failed cone is influenced by many factors, and the test results show great discreteness.

According to the test results, some specimens develop a double-cone failure mode as the anchor bolt diameter and buried depth both increase. In addition to the large-radius cone that controls the bearing capacity (line 2 in Fig.7(d)), some circular cracks are observed on the small shallow cone (line 1 in Fig.7(d)). This finding is similar to the observation in the experiment of an inorganic grouting anchor bolt (with a drilling diameter that is 2 to 4 times larger than that of an anchor bolt as shown, in Fig.2(b)).
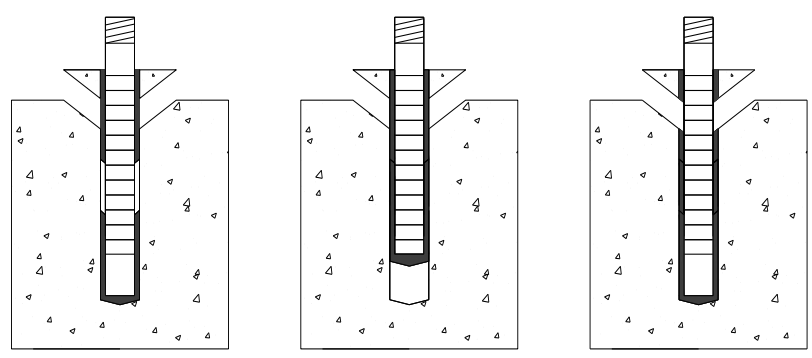

(a) Compound failure (b) Glue-concrete failure (c) Glue-bolt failure Fig. 6. Compound failure modes

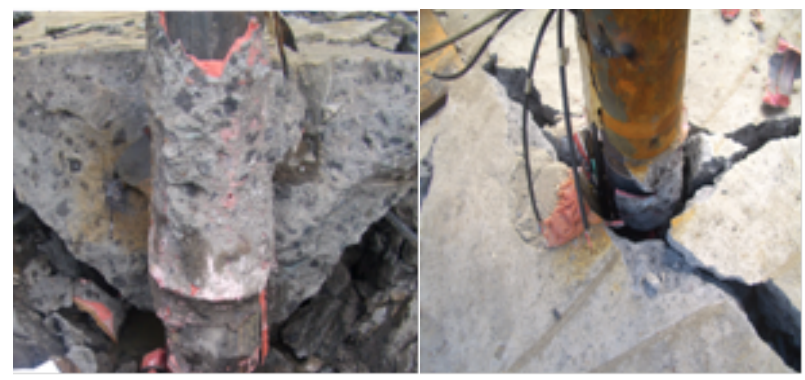

(a)

(b) 


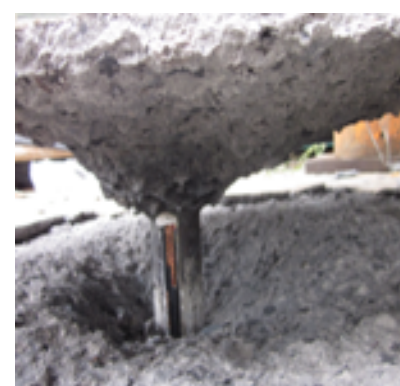

(c)

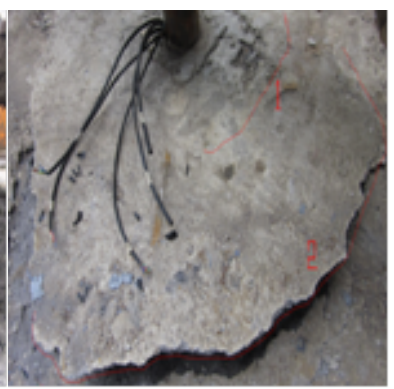

(d)

Fig. 7. Cone-bond failure

\subsection{Displacement of anchor bolt and loads}

The displacement measurement results at the loading end of the testing anchor bolt share the same variation trends with the corresponding load relation curve. The typical loaddisplacement relation curve is shown in Fig.8. The failure process of an anchor system under tensile loads throughout the loading process can be divided into elastic deformation and plastic failure.First, a linear relationship can be observed between the load and displacement of the anchor bolt when the load is low. As the load increases, the glue bonding reaches the linear limit and the linear stage ends. Second, when the bond stress exceeds the elastic limit, the curve slope begins to decrease and the upper concrete cone enters the plastic damage stage. Meanwhile, the bonding strength of the glue significantly decreases. With the continuous increase of load, the displacement of the anchor bolt develops and the anchoring system fails accordingly.

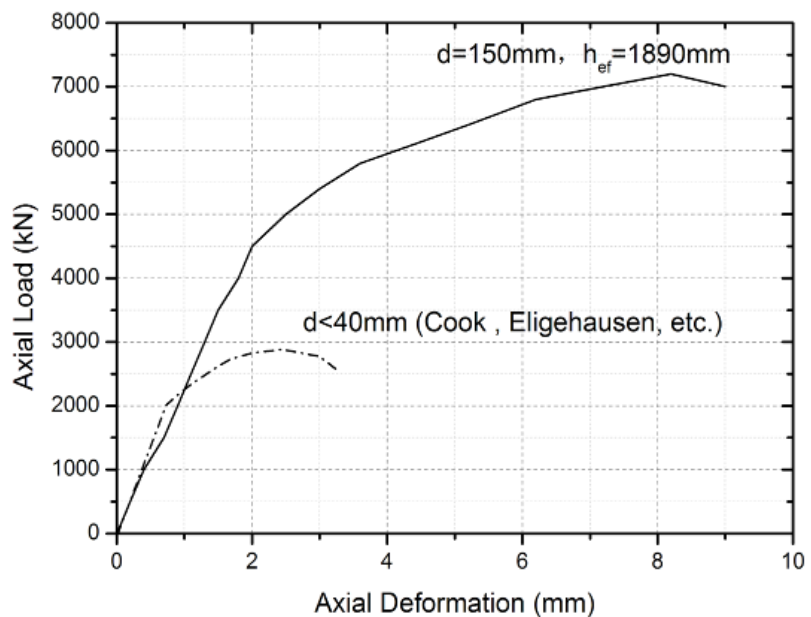

Fig. 8. Displacement-load curve

\subsection{Experiments on real-world networks}

Figs. 9(a) to 9(c) show the distribution of bond stress along the anchoring depth, which is calculated based on the axial stress of the anchor bolt under different loads when the buried depth/diameter is fixed and as the diameter increases (48, 90, and $150 \mathrm{~mm})$. When the tensile load is small, the stress distribution of the anchor bolt shows a concave distribution in the early loading stage, whereas the stress decreases along with an increasing buried depth. The stress of the anchor bolt tends to show a straight distribution along the anchoring depth while approaching the ultimate load. The bond stress in the glue layer gradually increases from the concrete surface to the range of the cone height and reaches its peak near the cone bottom. When the axial load is small, bond stress shows a hyperbolic functional distribution below the cone according to elastic theory [6]:

$$
\tau_{\max }=\frac{P}{\pi d\left(\frac{\sqrt{d}}{\lambda^{\prime}} \tanh \frac{\lambda h_{e f}}{\sqrt{d}}\right)}
$$

where $N_{u}$ is the axial load, and $\lambda^{\prime}$ is a parameter that is related to the shearing modulus of glue and the axial stiffness of the anchor bolt. This parameter can be obtained from an experiment. With the continuous increase of load, the bond stress tends to show a uniform distribution in the middle of the anchoring section. The mean bond stresses of the anchor bolts with different diameters (48, 90, and $150 \mathrm{~mm}$ ) are $9.98,8.52$, and $7.34 \mathrm{MPa}$, respectively. Moreover, bond stress rapidly declines along with an increasing bolt diameter. When the bolt diameter and absolute value of anchoring depth $\left(h_{e f}\right)$ both increase, the bond stress close to the bottom of the anchoring section gradually increases.

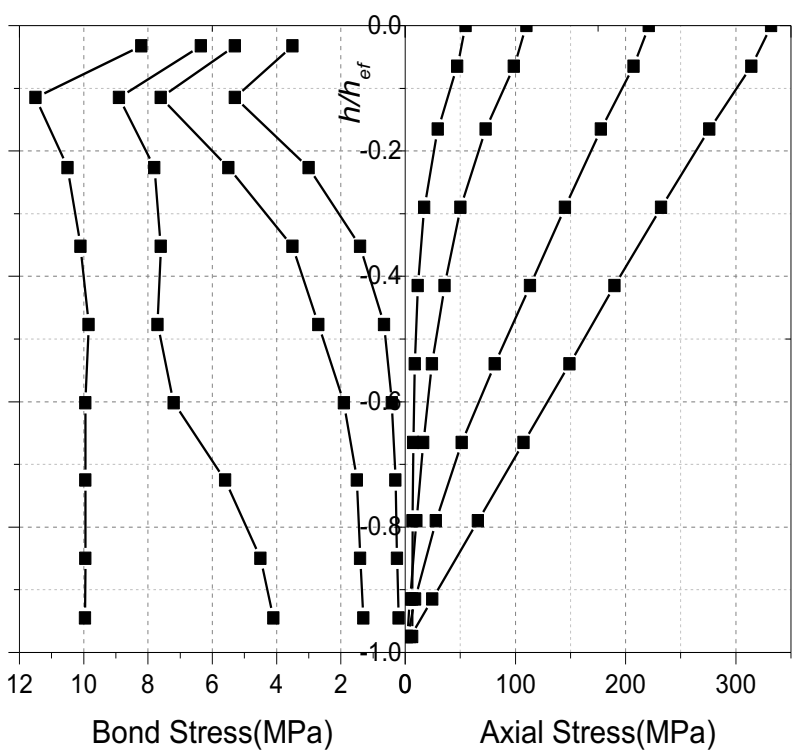

(a) $d=48 \mathrm{~mm}, \quad h_{e f}=400 \mathrm{~mm}$

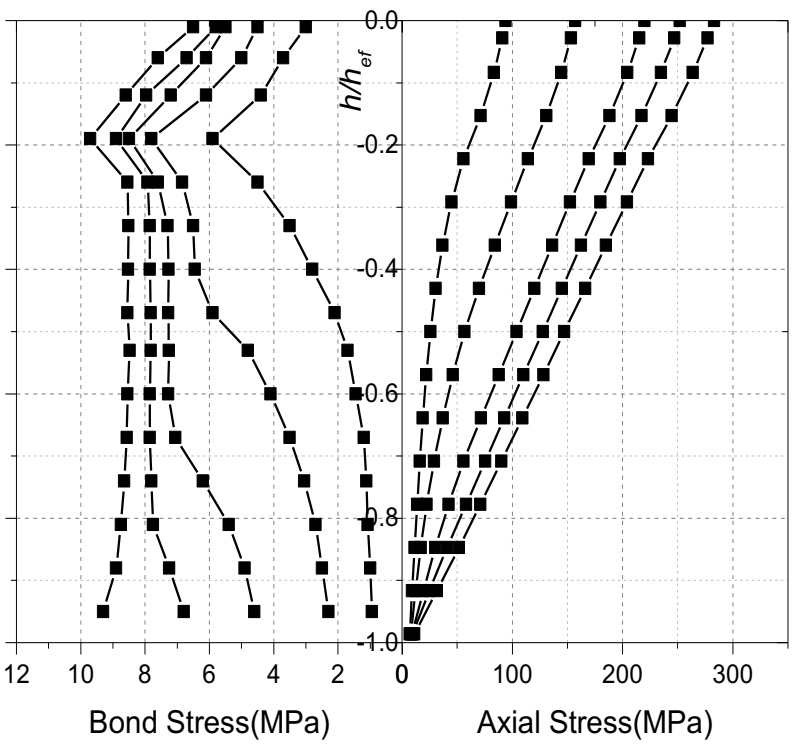

(b) $d=90 \mathrm{~mm}, h_{e f}=1200 \mathrm{~mm}$ 


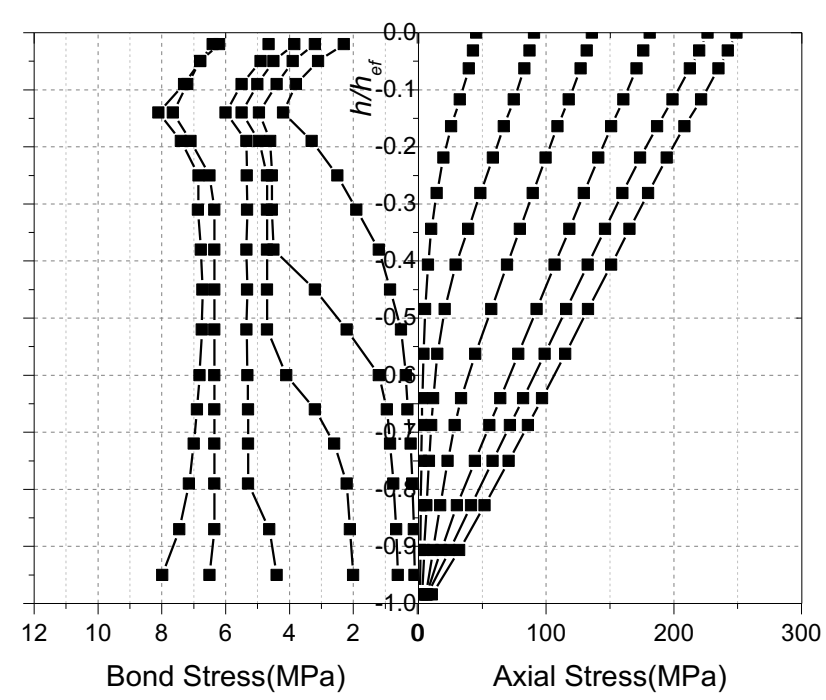

(c) $d=150 \mathrm{~mm}, \quad h_{e f}=1890 \mathrm{~mm}$

Fig. 9. Distribution of bond stress

Table 2. Test and numerical model results

\begin{tabular}{c|c|c|c|c|c}
\hline$d(\mathrm{~mm})$ & $h_{e f}(\mathrm{~mm})$ & $N_{t}(\mathrm{kN})$ & $N_{c}(\mathrm{kN})$ & $N_{t} / N_{c}$ & $h_{t c} / h_{c c}(\mathrm{~mm})$ \\
\hline \multirow{2}{*}{36} & 320 & 421 & 449 & 0.936 & $71 / 86$ \\
& 420 & 580 & 618 & 0.939 & $76 / 93$ \\
\hline \multirow{2}{*}{48} & 400 & 608 & 669 & 0.909 & $87 / 103$ \\
& 560 & 885 & 857 & 1.032 & 1.08 \\
\hline \multirow{2}{*}{90} & 720 & 2980 & 1684 & 1.08 & $3299 / 265$ \\
& 1100 & 4400 & 3907 & 1.13 & $430 / 357$ \\
\hline \multirow{2}{*}{150} & 1200 & 7200 & 6800 & 1.06 & $455 / 507$ \\
\hline
\end{tabular}

where $N_{t}$ is the test tensile capacity, $N_{c}$ is the numerical calculated tensile capacity, $h_{t c}$ is the test cone height, and $h_{c c}$ is the cone height in the calculation model.According to thef inite element analysis results, the concrete cone failure starts from the glue-concrete interface at the cone bottom and extends upward along the oblique plane of the cone to the concrete surface. This failure is mainly controlled by the concrete tensile. While approaching the ultimate loads, the bonding strength of the glue-concrete interface increases to some extent along with axial pressure, which is related to the dilatancy effect of materials. The crack on the slope of the cone extends to the concrete surface when reaching the ultimate loads and is accompanied by the bonding failure of the lower glue-concrete interface, thereby leading to a mixed failure phenomenon. The damages to concrete at ultimate loads are shown in Fig.10. Given the large diameter and buried depth of anchor bolts, hyperbolic failure is identified as the main failure mode, which is consistent with the experimental phenomena (Fig.11).

\subsubsection{Numerical simulation of bond stress}

Figs. 12(a) to 12(c) show the distribution of the bond stress of anchor bolts with different diameters along the anchoring depth under tensile loads in the finite element analysis under a fixed $h_{e f} / d=8$. The result in these figures shares the same variation trend as the test results. Figs.12(c) to 12 (d) reveal that when the anchor bolt diameter is fixed, the mean bond stress slightly changes along with an increasing buried depth The variations in bond stress along with the anchor bolt
4.4 Comparison between the finite element analysis and test results

\subsubsection{Design and manufacturing of specimens}

The test and finite element analysis results for the anchor bolt parameters(e.g., anchor bolt diameter, bolt layer thickness, and buried depth) under similar conditions were compared. The ratio between the test and finite element analysis results for ultimate tensile capacity ranged between 0.909 and 1.13 or 0.995 on average (Table 2). Consistent with the test results, the specimens developed a concrete cone + bonding failure mode. The height of the concrete cone is positively related with anchor bolt diameter, the ratio between cone height and anchoring depth $\left(h_{\text {cone }} / h_{\text {ef }}\right)$ ranges between 0.26 and 0.40 , and the angle of failed cone ranges between $35^{\circ}$ and $50^{\circ}$. According to the numerical analysis results, cone diameter is related to both the bonding performance of glue and concrete strength than to only. The element analysis results ranges between 0.83 and 1.14 or 0.93 on average. In sum, the finite element model can reflect the results of the actual test and the stress characteristics of the anchoring system. ratio of failed cone height between the test and finite are shown in Fig.13. The mean bond stress decreases from $12.16 \mathrm{MPa}$ at $30 \mathrm{~mm}$ to $7.78 \mathrm{MPa}$ at $150 \mathrm{~mm}$.
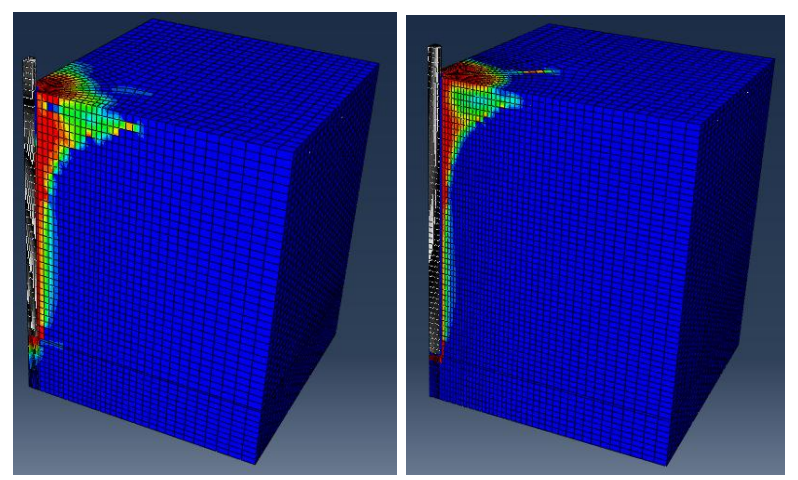

Fig. 10. Concrete failure contour $\left(d=48 \mathrm{~mm}\right.$ and $\left.90 \mathrm{~mm}, h_{e f}=12 d\right)$

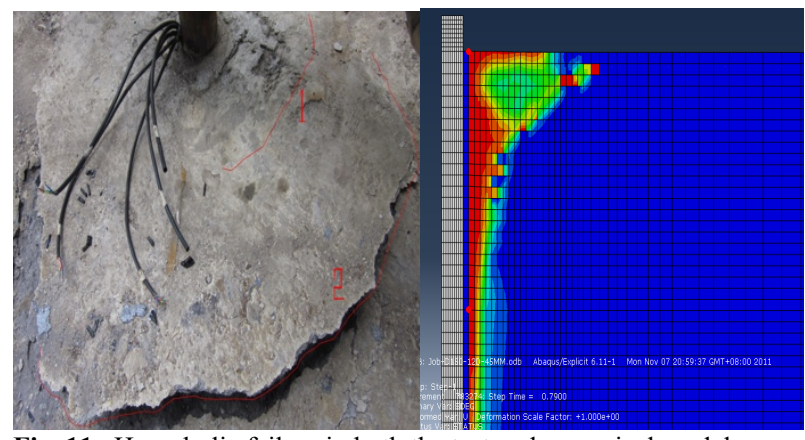

Fig. 11. Hyperbolic failure in both the test and numerical models 


\subsection{Calculation of tensile strength of PLA}

\subsubsection{Mean bond stress method}

For a large-diameter anchor, the shallowly buried $\left(5 d>h_{e f}\right)$ cone failure mode has few applications to acquire a sufficienttensile capacity and to reduce the mutual influences of anchor bolts. Controlling the anchor bolt materials requires a significantly high anchoring depth that exceeds the capacity of the concrete base, which poses a huge challenge in practical construction. Therefore, the compound failure mode has become common in engineering, and the method for calculating ultimate tensile capacity has important practical values. Based on previous studies and the analysis results, the bond stress of large-diameter bolts follows a uniform distribution in most positions while approaching the ultimate loads, and such distribution can be calculated according to a uniformly distributed bond stress. The glue-bolt and glue-concrete interface failures are often difficult to be determined due to the changing and difficultto-control drilling diameter $\left(d_{0}\right)$ and the thin chemical bonding layer. Therefore, calculating the bond area based on anchor bolt diameter will not produce much errors. The bearing capacity $\left(N_{u}\right)$ is expressed by a uniformly distributed bond stress model.

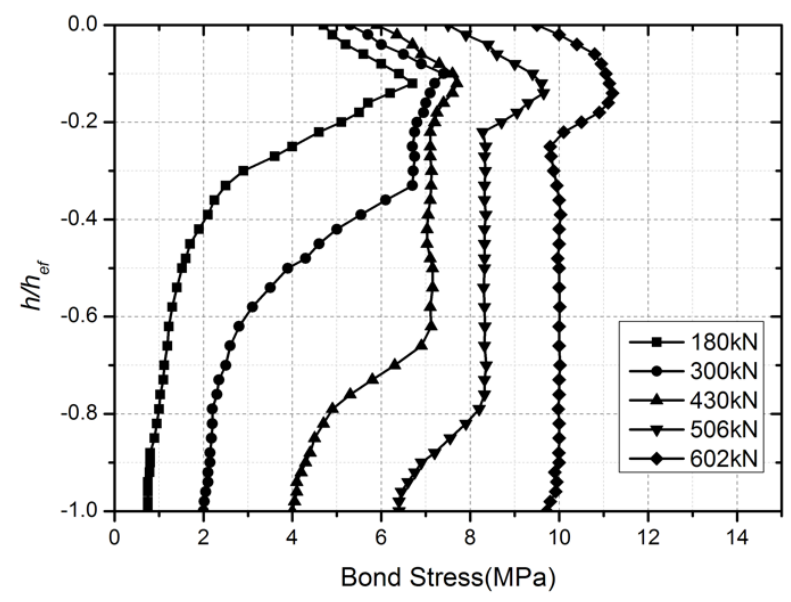

(a) $d=48 \mathrm{~mm}, h_{e f}=400 \mathrm{~mm}$

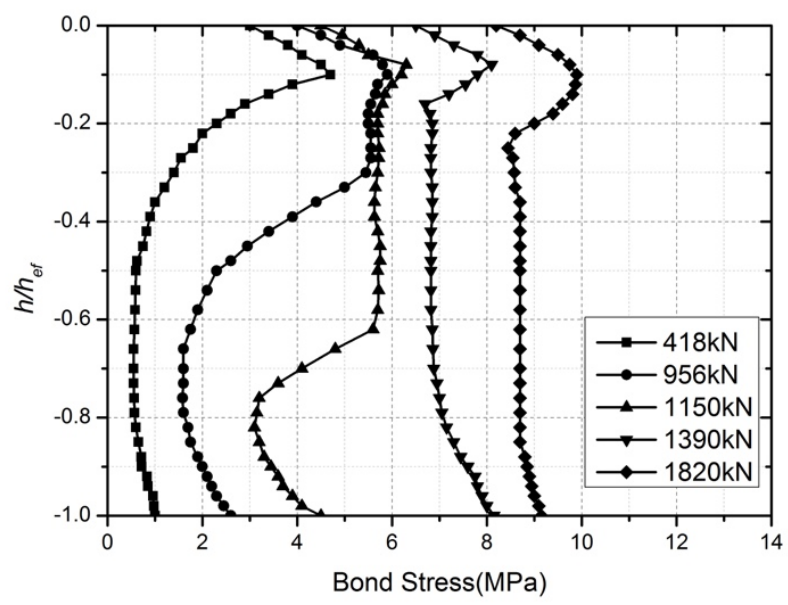

(b) $d=90 \mathrm{~mm}, h_{e f}=720 \mathrm{~mm}$

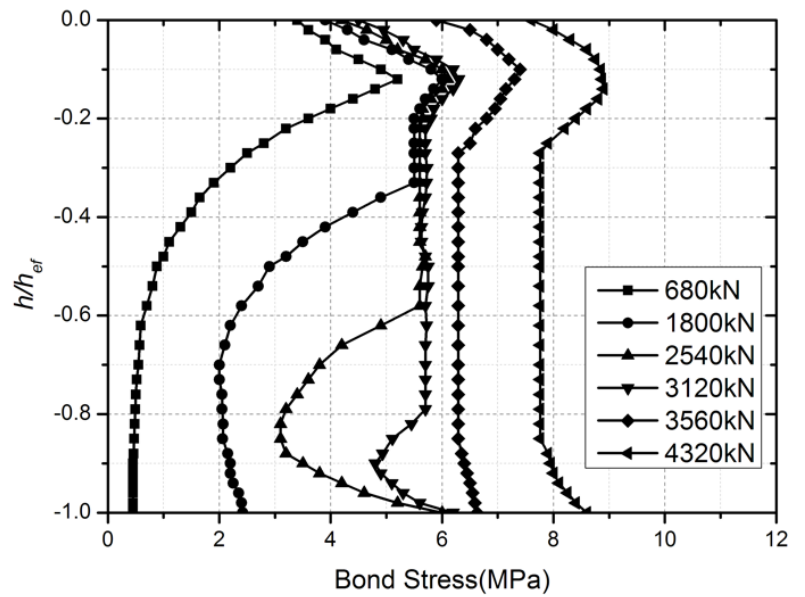

(c) $d=150 \mathrm{~mm}, h_{e f}=1200 \mathrm{~mm}$

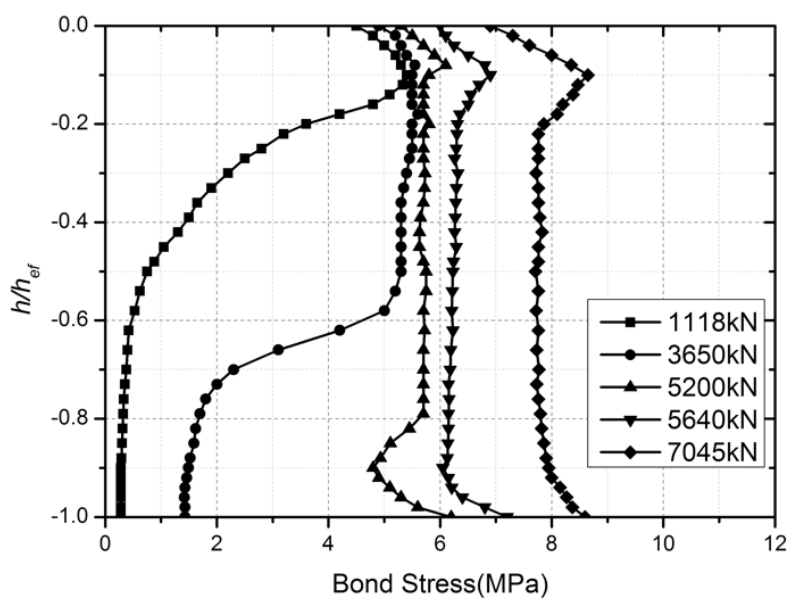

(d) $d=150 \mathrm{~mm}, h_{e f}=1890 \mathrm{~mm}$

Fig. 12. Distribution of bond stress

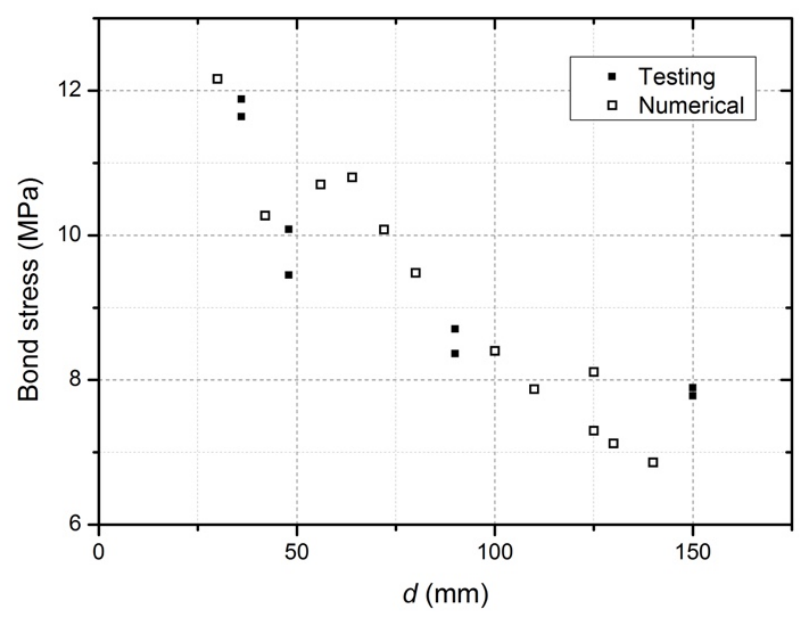

Fig. 13. Relationship between mean bond stress and anchor bolt diameter

Nevertheless, when the anchor bolt diameter is small and changes within a small interval, $\tau$ in Equation (3) only changes along with the type of glue. For the same type of glue, the mean bond stress is relatively concentrated. Cook[20] argued that the middle value can be determined according to the product test results. The mean bond stress of the large-diameter anchor bolt in the whole section obviously decreases along with an increasing diameter. Therefore, the influence of anchor bolt diameter on bond 
stress must be considered. The following corrected bond shearing stress can be used:

$$
N_{u}=\tau_{d} \pi d h_{e f}
$$

where $\tau_{d}=\alpha d+\beta, \alpha$, and $\beta$ are the coefficients related to anchor bolt diameter and type of adhesive. The variation law of the mean bonding strength of different types of bonding materials and anchor bolt diameter can be established according to the relevant test standards of adhesive products.

\subsubsection{Statistical correction method based on CCD}

After transforming Equation (2), the formula for calculating tensile capacity can be expressed as follows based on the elastic formula:

$$
P=\pi \tau_{\max } d\left(\frac{\sqrt{d}}{\lambda^{\prime}} \tanh \frac{\lambda^{\prime} h_{e f}}{\sqrt{d}}\right)
$$

By combining Equations (3) and (4), let $N_{u}=P$, which can be simplified as:

$$
\frac{\tau_{d}}{\tau_{\max }}=\frac{\tanh \frac{\lambda^{\prime} h_{e f}}{\sqrt{d}}}{\frac{\lambda^{\prime} h_{e f}}{\sqrt{d}}}
$$

Based on the test data of anchor bolts with different diameters and the findings of Muratli [15], Cook et al. analyzed the test data of anchor bolts with a small diameter (12mm to $32 \mathrm{~mm}$ ) and found that $\tau_{d} / \tau_{\max }$ ranges between 0.836 and 0.977 whereas $\lambda^{\prime}$ ranges between 0.011 and 0.020. In this study, $\tau_{d} / \tau_{\max }=0.9$ and $\lambda^{\prime}=0.014$, which are integrated into Equation (5) and are solved by using $h_{e f} / \sqrt{d}$ as an unknown number. Equation (5) yields the same results as Equations (3) and (4) when $h_{e f} / \sqrt{d}<50$. This finding also conforms to the previous experimental results. However, the calculation error between Equations (3) and (4) increases along with anchor bolt diameter when $h_{e f} / \sqrt{d}>50$. Nevertheless, the results of both these equations are significantly smaller than the test results (Fig.14).

When the anchor bolt diameter is small and shows slight changes, $\tau_{d}$ in Equation (3) is relatively concentrated under different types of adhesives and has a large numerical value (approximately $8 \mathrm{MPa}$ to $14 \mathrm{MPa}$ )[25]. However, the mean bond stress of a large-diameter anchor bolt in the whole anchoring section significantly decreases along with an increasing diameter. Parameters such as $\tau_{0}$ and $\lambda^{\prime}$ are generally absent from a preliminary engineering design, thereby hindering the application of Equations (3) and (4). The ultimate bearing capacity can be computed as follows based on CCD (with a 95\% assurance rate and a coefficient of variation of 0.2$)$ [26]:

$$
N_{u}=13.5 \phi_{a} h_{e f}^{1.5} \sqrt{f_{c}}
$$

where $\phi_{a}=\left\{\begin{array}{l}1+3 A_{b}^{-0.2}, 150 \mathrm{~mm}>d \geq 50 \mathrm{~mm} \\ 1,36 \mathrm{~mm}<d<50 \mathrm{~mm}\end{array}\right.$

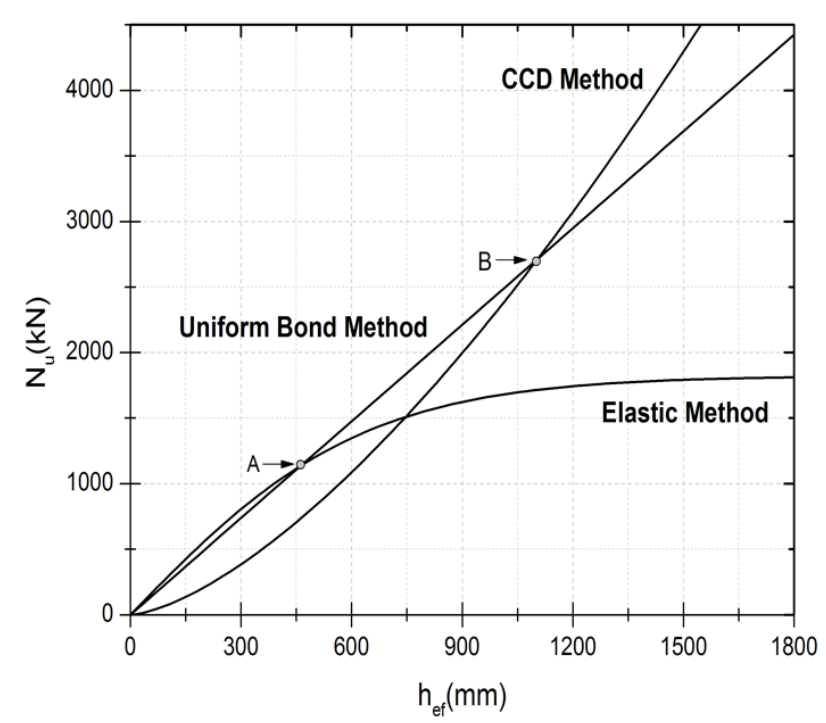

Fig. 14. Comparison of functions $\left(d=90 \mathrm{~mm}, \tau_{0}=8.7 \mathrm{MPa}, \tau_{\max }=\right.$ 10.2 $\left.\mathrm{MPa}, \lambda^{\prime}=0.015\right)$

The coefficient $k_{c}$ is equal to 13.5. Therefore, the ultimate tensile capacity of the anchoring system in Equation (6) is described as a variable related to anchoring depth $h_{e f}$, anchor bolt diameter $d$, and concrete strength $f_{c}$. The calculation also considers the major factors that influence the bearing capacity of the system. The calculation results are shown Table 3 and Fig. 12.

Fig. 12 shows that the elastic formula (4) is very similar to the UBS formula (3) before point A ( $h_{e f}=472 \mathrm{~mm}$ ) because $h_{e f}<5 d$ before this point. Controlled by the cone failure mode, the bond stress distribution under the ultimate load is determined as a single mode. The bond stress of the anchoring section in the cone range and close to the bottom interval is significantly higher than that in the middle UBS section when the anchoring depth increases and tends to compound failure. Moreover, the height and diameter of the failed cone are positively related to anchor bolt diameter. The additional bonding force provided by the height and diameter of the failed cone further leads to the failure of the elastic formula and mean bonding strength. The CCD formula and Equation (6) show similar development trends but gradually exceed the mean bond shearing stress formula along with an increasing anchor bolt diameter after point A. Moreover, Equation (6) increases faster than the CCD formula because CCD is based on the test database of a small-diameter anchor bolt, which does not consider the size effect of anchor bolt diameter. In specific engineering design, the ultimate bearing capacity of a single anchor is estimated by using Equation (6). A certain reduction coefficient is also selected to guarantee design safety. 
Table. 3. Experimental results of the SFI and netscience networks. For the Ncut method, the preassigned cluster numbers for the SFI and netscience networks are set to 7 and 100, respectively

\begin{tabular}{|c|c|c|c|c|c|c|c|c|}
\hline$d(\mathrm{~mm})$ & $h_{e f}(\mathrm{~mm})$ & $\tau_{0}(\mathrm{MPa})$ & $\tau_{\max }(\mathrm{MPa})$ & $\lambda^{\prime}(\mathrm{mm}-0.5)$ & $\mathrm{Nt}(\mathrm{kN})$ & Eq.15(kN) & $\mathrm{CCD}(\mathrm{kN})$ & Eq.17(kN) \\
\hline 36 & 320 & 11.64 & 14.5 & 0.018 & 421 & 406 & 423 & 423 \\
\hline 36 & 420 & 11.88 & 14.8 & 0.017 & 580 & 490 & 636 & 636 \\
\hline 48 & 400 & 10.08 & 11.7 & 0.015 & 608 & 568 & 592 & 592 \\
\hline 48 & 560 & 9.45 & 11.5 & 0.012 & 885 & 749 & 979 & 979 \\
\hline 90 & 720 & 8.7 & 10.2 & 0.015 & 1820 & 1483 & 1429 & 1800 \\
\hline 90 & 1100 & 8.36 & 10.4 & 0.014 & 2980 & 1844 & 2588 & 3183 \\
\hline 150 & 1200 & 7.78 & 9.7 & 0.016 & 4400 & 3206 & 3386 & 4130 \\
\hline 150 & 1890 & 7.89 & 9.9 & 0.012 & 7200 & 4530 & 6076 & 7230 \\
\hline
\end{tabular}

\section{Conclusions}

To develop a method for calculating the tensile capacity of PLAs, the compound failure mode of anchor systems was analyzed based on the results of previous tests. The distribution curve of bond stress along anchoring depth was calculated based on the axial stress of anchor bolts. The bond stress gradually attenuated along with an increasing anchor bolt diameter. A formula for calculating the ultimate bearing capacity of large-diameter anchor bolts was then built based on the corrected mean bond stress and CCD. The following major conclusions can be drawn from this work:

(1) Similar to the force transferring mechanism on a small-diameter anchor $(d<36 \mathrm{~mm})$, the PLA mainly demonstrated a concrete cone + bonding failure. When the anchoring depth was relatively large, the concrete demonstrated a hyperbolic cone failure, retained a largeradius cone, and controlled the failure bearing capacity of the cone.

(2) The failure process of the anchoring system could be divided into elastic deformation and plastic failure under tensile loads. In the elastic stage, the bond stress on the interface demonstrated a hyperbolic functional distribution in the elastic stage. While approaching the ultimate tensile capacity, the bond stress in the middle section showed a straight distribution.

(3) The value of bond stress was slightly influenced by the anchor bolt diameter at an ultimate rate. The effects of anchor bolt diameter on bond stress should be considered when calculating ultimate tensile capacity based on the formula for calculating mean bond stress.

(4) A formula for calculating the ultimate tensile capacity of PLAs was then designed based on the test data. This formula was proven reasonable by comparing the test results with the finite element simulation results. This formula could be used in calculating the ultimate tensile capacity of post-installed $40 \mathrm{~mm}$ to $150 \mathrm{~mm}$ large-diameter anchors.

In sum, the proposed method for calculating the ultimate tensile capacity of PLAs based on corrected mean bond stress and CCD considered not only the failure mode characteristics of the anchoring system, but also the bonding stress attenuation caused by anchor bolt diameter. The proposed method has a simple concept and form and can be easily applied in engineering practice. The findings of this work can provide theoretical references for the future design of PLA tensile strength.

\section{Acknowledgements}

This work was supported by the National Natural Science Foundation of China (Project No. 51608081) and the Scientific and Technological Research Program of the Chongqing Municipal Education Commission (No. KJQN201800743, No. KJ1600532).

This is an Open Access article distributed under the terms of the Creative Commons Attribution License

\section{References}

1. Christoph Mahrenholtz, Rolf Eligehausen, Tara C. Hutchinson, and Matthew S. Hoehle, "Behavior of Post-Installed Anchors Tested by Stepwise Increasing Cyclic Crack Protocols". ACI Structural Journal, 114(3), 2017, pp.621-630.

2. Zhao Ningyu, Chen Zhuo, "Nonlinear numerical analysis and experiment comparision of post-installed large-diameter anchor". Building Structure, 45(2), 2015, pp. 36-41 (in Chinese).

3. R. A. Cook, D. O. Prevatt, S. A. Dalton, "Base Connectionsfor Signal/Sign Structures". 2012, Florida:. Department of Civil and Coastal Engineering College of Engineering, University of Florida.

4. Mallee R, Eligehausen R, Bergmeister K, et al., "Design of Fastenings for Use in Concrete". ACI Structural Journal, 110(9), 2013, pp.109-112.

5. Kenton E. McBride, Ronald A. Cook, David O. Prevatt, William Potter, "Anchor Bolt Steel Strength in Annular Stand-Off Base Plate Connections".Journal of the Transportation Research Board, 2406(1), 2014, pp.23-31.

6. Michael MacVay, Ronald A. Cook, "Pullout simulaiton of postinstalled chemically bonded anchors". Journal of Structural Engineering, 122(9), 1996, pp. 1016-1024.

7. J.Appl, Eligehausen R., "Groups of bonded anchors-design concept", 2003, report no03/27-2/55, university of stuttgart. Stuttgart.

8. RA.Cook., "Loss and Recovery of Critical Lifelines Following Recent Hurricanes". Lifeline Earthquake Engineering, 35(1), 2015, pp. 22-35.
9. Fuchs,W.;Eligehausen,R; and Breen,J.E., "Concrete Capacity Design(CCD) approach for fastening to concrete". ACI Structrual Journal, 92(1), 1995, pp. 73-94.

10. Zhou Xingang, Wang Youxuan, Qu Shuying, "Ultimaate Load Carrying Capacity Analysis of Adhesively Bonded Bars in Concrete". Engineering Mechanics, 19(6), 2002, pp. 82-86.(in Chinese).

11. Eligehausen R, Popov E P, Bertero V V., "Local Bond stress slip relationship of deformed bars under generalized excitations". In: Proceedings of the 31th European Conference on Earthquake Engineering, Athens, Greece: Springer, 2016, pp. 68-80.

12. Keun-Hyeok Yang and Ashraf F. Ashour., "Mechanism analysis for concrete breakout capacity of single anchors in tension". $A C I$ Structural Journal,105(5), 2018, pp.609-616.

13. Mahrenholtz P, Eligehausen R, Hutchinson T., "Correlation of anchor load and crack width amplitudes for anchors connecting non-structural components to concrete". In: Proceedings of the Vienna Congress on Recent Advances in Earthquake Engineering and Structural Dynamics, Vienna, Austria: Springer, 2013, pp. 276282.

14. Akanshu Sharma, R. Eligehausen, J. Hofmann., "Numerical Modeling of Joints Retrofitted with HaunchRetrofit Solution". ACI Structural Journal, 111(4), 2014, pp.861-871. 
15. Muratli, Hakki; Klingner, Richard E.; Graves III, Herman L., "Breakout capacity of anchors in concrete- part 2: shear". ACI Structural Journal. 101(6), 2004, pp.188-201.

16. F. Delhomme, G. Debicki., "Numerical modelling of anchor bolts under pullout and relaxation tests". Construction and Building Materials, 24, 2010, pp.1232-1238.

17. Shutong Yang, Zhimin Wu,Xiaozhi Hu,Jianjun Zheng., “Theoretical analysis on pullout of anchor from anchor-mortar-concrete anchorage system". Engineering Fracture Mechanics, 75( 5) , 2008 , pp.961-985.

18. Ožbolt J, Eligehausen R, Periškić G, et al., "3D FE analysis of anchor bolts with large embedment depths". Engineering Fracture Mechanics, 74(1), 2007, pp.168-178.

19. Mallee R, Eligehausen R, Bergmeister K, et al., "Design of Fastenings for Use in Concrete". NJ : Wiley, 2013, pp.172.

20. Cook R A., "Adhesive Anchors in Concrete Under Sustained Loading Conditions". Transportation Research Board of the National Academies, 2009.
21. K. E. Mc Bride, R. A. Cook, and D. O. Prevatt, "Steel Shear Strengthof Anchors With Stand-off Base Plates". Florida: Department of Civil and Coastal Engineering College of Engineering, University of Florida, 2013, Report No. BDK75 97749.

22. Eligehausen R, Popov E P, Bertero V V., "Local Bond stress slip relationship of deformed bars under generalized excitations". Report UCB/EERC-83/23, University of California, 2016, pp.6880 .

23. Sadie A. Dalton, "Base Connections for Signal and Sign Structures". Master thesis of University of Florida. USA, 2011, pp. 53-76.

24. J. LUBLINER; Javier Oliver; Sergio Oller; Eugenio Oñate, "A Plastic-Damage model for Concrete". International Journal of Solids and Structures, 25(3), 1989, 299-326.

25. Krzywiński, K.; Sadowski, Ł., "The Effect of Texturing of the Surface of Concrete Substrate on the Pull-Off Strength of Epoxy Resin Coating". Coatings, 9(2), 2019, pp.143-155.

26. Piotr Dybeł, Daniel Wałach, Krzysztof Ostrowski, "The Top-Bar Effect in Specimens with a Single Casting Point at One Edge in High-Performance Self-Compacting Concrete". Journal of Advanced Concrete Technology, 16 (7), 2018, pp.109-121. 